\title{
EFEKTIVITAS MODEL KOOPERATIF TIPE COURSE REVIEW HORAY (CRH) TERHADAP HASIL BELAJAR FISIKA SISWA
}

\section{EFFECTIVENESS OF COOPERATIVE MODEL TYPE COURSE REVIEW HORAY (CRH) TOWARDS STUDENTS 'LEARNING OUTCOMES OF PHYSICS}

\author{
Fepti Bunga Mutiara ${ }^{1}$, Happy Komikesari ${ }^{2}$, Nur Asiah ${ }^{3}$ \\ ${ }^{1,2}$ Prodi Pendidikan Fisika Fakultas Tarbiyah dan Keguruan Universitas Islam Negeri Raden Intan Lampung \\ ${ }^{3}$ Pendidikan Agama Islam Fakultas Tarbiyah dan Keguruan Universitas Islam Negeri Raden Intan Lampung \\ E-mail: feptibunga58@gmail.com
}

Diterima: 10 Januari 2019. Disetujui: 03 Februari 2019. Dipublikasikan: 29 Maret 2019

\begin{abstract}
This study aims to determine the effectiveness of cooperative model type Course Review Horay (CRH) on Student Learning Outcomes and Science Process Skills (KPS) in Class XI at Bandar Lampung SMAN 9. The research method used. quasi experiment with non equivalent control group design. The sampling technique used was purposive sampling. The results of the hypothesis test analysis using the Maan Whitney test showed a significant value of 2 taile $=0.00$ with a significant level of $0.05 \%$. It states that the significance value is less than 0.05 (0,000). The CRH learning model is more effective towards students' learning outcomes, effectiveness can be seen by the effect size test. The result of the effect size test is 1.41 so that it is included in the high category.
\end{abstract}

Keywords: learning outcomes, course review horay, CRH learning

Abstrak: Penelitian ini bertujuan untuk mengetahui Efektifitas Model kooperatif Tipe Course Review Horay (CRH) Terhadap Hasil Belajar Siswa Dan Keterampilan Proses Sains (KPS) Pada Kelas XI Di SMAN 9 Bandar Lampung. Metode penelitian yang digunakan. quasi eksperimen dengan desain non equivalent control group. Teknik pengambilan sampel yang digunakan adalah purposive sampling. Hasil analisis uji hipotesis menggunakan uji Maan Whitney menunjukan nilai signifikn 2 taile $=0,00$ dengan taraf signifikan $0,05 \%$. Hal tersebut menyatakan bahwa nilai signifikansi lebih kecil dari $0,05(0,000)$. Model pembelajran CRH lebih efektiv terhadap hasil belajar peserta didik, keefetivan dapat dilihat dengan uji effect size. Hasil dari uji Effect size yaitu 1,41 sehingga termasuk dalam kategori tinggi.

(C) 2018 Unit Riset dan Publikasi Ilmiah FTK UIN Raden Intan Lampung

Kata kunci: hasil belajar, course review horay, pembelajaran CRH

\section{PENDAHULUAN}

Pendidikan ialah salah satu cara untuk menaikkan kualitas kehidupan manusia diera sekarang dan yang akan datang, sebab dengan adanya pendidikan akan mendapatkan pengalaman yang bermanfaat bagi hidupnya, jadi pola berpikir dapat berkembag sertra berbagai potensi yang dimilikinya juga, kemudian mempunyai pandangan untuk mewujudkan harapan untuk kehidupan yang lebih baik.(meidian kusumawati, 2014) pendidik yang sangat mempengaruhi kualitas para peserta didik. Peran utama guru adalah merancang, mengelola, mengevaluasi dan terus menerus menindak lanjuti permasalahan dalam 
pembelajaran.(Desy, Sari, \& Tastra, 2016) pendidik harus menciptakan suasana pembelajaran yang terencana. Serta mempunyai kekuatan spiritual keagamaan, pengendalian diri, kepribadian kecerdasan, akhlak mulia, serta keterampilan yang diperlukan dirinya, masyarakat, bangsa dan negara.

Keberhasilan prestasi belajar siswa disebabkan oleh beberapa faktor. Faktor dari luar yaitu faktor dari luar siswa, antara lain lingkungan keluarga, masyarakat, dan sarana pendukung. Faktor dari dalam yaitu faktor dari dalam diri siswa, seperti kecerdasan, kemampuan, kemauan, kreativitas, dan keadaan fisik.(Pramadita, Mashuri, \& Arifudin, 2013). Maka pendidik juga harus memiliki strategi pembelajaran agar proses pembelajaran dapat berjalan dengan efektiv. Fungsi dari model pembelajaran yaitu untuk menciptakan suasana belajar yang menyenangkan dan tidak jenuh sehingga dapat memacu peserta didik untuk berpikir kreatif. (Rozi, 2014)

Kompetensi guru ialah bagaimana ia mampu memandu dan menciptakan proses belajar agar dapat mencapai terget kompetensi yang hendak di capai.(Aris, 2014) Fisika adalah bidang ilmu yang mempelajari alam dan gejalanya, dari yang bersifat nyata sampai yang bersifat abstrak.(Sugianti \& Lesmono, 2017) Dalam mempelajari fisika kita dapat memahami alam sekitar dengan penyelidikan dan membentuk sebuah pengetahuan.(Haris \& Amal, 2016) Fisika salah satu mata pelajaran yang kurang diminati, karena kebanyakan peserta didik menganggap bahwa belajar fisika itu sulit. (Indrawati \& Harijanto, 2017)

Model Course Review Horay yaitu kegiatan belajar yang memprioritaskan pada pemahaman materi yang guru ajarkan dengan menyelesaikan soal- soal (Mahanani, Suhito, \& Mashuri, 2013)
Kegiatan belajar lebih berpusat pada peserta didik. Dengan keadaan belajar yang mengasyikan membuat siswa lebih merasakan nyaman saat pelajaran berlangsung sehingga siswa tidak merasakan bosan dan tegang ketika mengikuti pembelajaran.(Komikesari, 2016) Proses pembelajaran yang menyenangkan akan memotivasi peserta didik untuk lebih semangat lagi dalam belajar Fisika.

\section{LANDASAN TEORI}

Model pembelajaran mengacu pada pendekatan pembelajaran yang akan digunakan, termasuk di dalamnya tujuantujuan pengajaran, tahap-tahap dalam kegiatan pembelajaran, lingkungan pembelajaran, dan pengelolaan kelas.(Afandi, Evi, \& Puspita Wardani Oktarina, 2013).

Pencapaian pemahaman konsep fisika yang lebih baik, ditinjau dari sikap ilmiah diperlukan suatu model pembelajaran yang berupaya menanamkan dasar-dasar berpikir ilmiah pada diri peserta didik. Pembelajaran fisika tidak hanya ditekankan pada pengetahuan fakta-fakta, penghafalan rumus tetapi perlu dilengkapi dengan pemahaman konsep yang mendasar.(Saregar, Marlina, \& Kholid, 2017)

Belajar itu sendiri merupakan suatu proses dari seseorang yang berusaha untuk memperoleh suatu bentuk perubahan prilaku yang relative menetap. Belajar merupakan langkah- langkah atau prosedur yang ditempuh. Bukti bahwa seseorang telah belajar ialah terjadinya perubahan tingkah laku pada seseorang tersebut.(Diani, Yuberti, \& Syafitri, 2016) Hal tersebut perlu adanya model pembelajaran yang menyenangkan.

Model pembelajaran CRH adalah model pembelajaran dengan pengujian pemahaman menggunakan kotak yang diisi dengan nomor untuk menuliskan jawaban 
(Pramadita et al., 2013) Course Review Horay (CRH) mempunyai ciri-ciri selain pengembangan aktivitas berpikir juga menumbuhkan perilaku-perilaku sosial yang positif yang dapat dikembangkan melalui diskusi maupun kerja kelompok sehingga akan meningkatkan aktivitas siswa (Setiyaningsih, 2014)

Model pembelajaran Course Review Horay (CRH) membuat siswa menjadi lebih aktif karena siswa belajar secara berkelompok dengan menyenangkan.(Desy et al., 2016) Course Review Horay (CRH) mempunyai karakteristik, yaitu merupakan pembelajaran kooperatif yang melibatkan aktivitas seluruh siswa dimana pembelajaran berpusat pada siswa (Setiyaningsih, 2014). Model pembelajaran Course Review Horay (CRH) juga termasuk model pembelajaran yang inovatif sehingga dapat meningkatkan hasil belajar siswa. Selain itu dengan menerapkan model pembelajaran $\mathrm{CRH}$ dapat memacu siswa untuk berkompetisi serta melatih kerjasama antar siswa dalam menjawab pertanyaanpertanyaan yang diberikan.(Ani, Garminah, \& Suartama, 2016)

\section{METODE PENELITIAN}

Metode penelitian yang digunakan. Kuasi eksperimen dengan desain non equivalent control group. Penelitian ini menggunakan satu variabel bebas dan dua variabel terikat, variabel bebas yaitu model kooperatif $\mathrm{CRH}$ dan variabel terikatnya yaitu hasil belajar dan keterampilan proses sains. Peneltian ini dilaksanakan di SMAN 9 Bandar Lampung Pada bulan September 2018. Populasi berjumlah 245, dengan sampel kelas XI IPA 4 sebagai kelas Eksperimen dan kelas XI IPA 3 sebagai kelas kontrol.

Teknik pengambilan sampel dilakukan dengan purposive sampling dengan memandang bahwa anggota populasi dianggap homogen. Instrument penelitian ini menggunakan test essay sebanyak 10 soal untuk mengetahui hasil belajar. Sebelum soal dignakan untuk penelitian terhadap hasil belajar terlebih dahulu di uji validitas, reabilitas, daya beda, dan tingkat kesukaran. Analisis data menggunakan excel dan untuk menguji normalitas, homogenitas, dan hipotesis menggunakan SPSS 17.

Untuk mengetahui efektivitas penggunaan model pembelajaran course review horay $(\mathrm{CRH})$ terhadap hasil belajar peserta didik maka analisis data pada penelitian ini menggunakan statistik dengan melakukan pengujian terhadap nilai pretest dan post-test peserta didik. Uji yang dilaksanakan berupa uji normalitas, homogenitas, dan uji statistik, selanjutnya data yang di dapat untuk menguji hipotesis menggunakan Effect Size.

\section{HASIL DAN PEMBAHASAN}

Tes hasil belajar dilaksanakan pada awal dan pertemuan terakhir proses pembelajaran. Data tersebuut disajikan dalam bentuk tabel.

Tabel 1. Hasil belajar

\begin{tabular}{lll}
\hline \multirow{2}{*}{ Kelas } & \multicolumn{2}{l}{ Rata-Rata Nilai } \\
\cline { 2 - 3 } & Pretest & Posttest \\
\hline Kontrol & 48,6 & 71,0 \\
\hline Eksperimen & 52,8 & 83,6 \\
\hline
\end{tabular}

Berdasarkan tabel diatas menunjukkan bahwa nilai pretest dan posttest kontrol lebih rendah dibandingkan kelas eksperimen.

Untuk menganalisis kategori tes hasil belajar siswa digunakan skor gain ternormalisasi, $N$-Gain diperoleh dari pengurangan skor posttes dengan skor pretest dibagi oleh skor maksimum dikurang skor pretest. Hasil dari perhitungan $N$-Gain ini akan digunakan untuk uji effect size. Data disajikan dalam diagram di bawah ini. Perolehan $N$-Gain 
hasil belajar peserta didik dari kelas ekperimen dan kelas kontrol dapat dilihat pada Tabel 2

Tabel 2. Hasil N-Gain Hasil belajar

\begin{tabular}{lll}
\hline Kelas & N-Gain & $\begin{array}{l}\text { Rata-Rata } \\
\text { Nilai }\end{array}$ \\
\hline Kontrol & 0,43 & Sedang \\
\hline Eksperimen & 0,66 & Sedang \\
\hline
\end{tabular}

Data disajikan dalam diagram di bawah ini

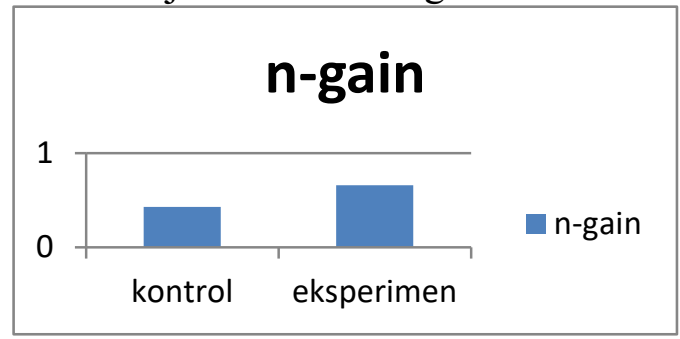

Gambar 1. Diagram nilai n-gain
Pengujian prasyarat dilakukan dengan tujuan untuk apakah data yang diperoleh terdistibusi normal dan homogen.

1. Uji Normalitas

Pengujian yang digunakan untuk mengetahui data terdistribusi normal atau tidak dalam penelitian ini yaitu menggunakan kolmogorov-smirnov menunjukan data terdistribusi normal. Berdasarkan hasil uji normalitas posttest dengan taraf signifikan 0,05 . Jika $\mathrm{L}_{\text {hitung }}<$ $\mathrm{L}_{\text {tabel }}$ maka data berdistribusi normal.

Tabel 3. Hasil Uji Normalitas Posttest Dan Pretest Kelas Kontrol Dan Kelas Eksperimen

\begin{tabular}{lllll}
\hline \multirow{2}{*}{ Data } & \multicolumn{2}{c}{ Posttest Dan Pretest } & Kontrol \\
& Postest & Eksperimen & Postest & Pretest \\
\hline Jumlah peserta didik (N) & 35 & 35 & 34 & 34 \\
$\alpha$ & 0,05 & 0,05 & 0,05 & 0,05 \\
Sig & 0,249 & 0,01 & 0,345 & 0,324 \\
Kesimpulan & Normal & Tidak normal & Normal & Normal \\
\hline
\end{tabular}

2. Uji Homogentias

Uji homogenitas ini dilakukan sebagai prasyarat yang kedua dalam menentukan uji hipotesis yang akan digunakan. Hasil homogenitas posttest kelas kontrol dan kelas eksperimen menggunakan uji Levene's. Demikian dapat disimpulkan bahwa $\mathrm{H}_{0}$ diterima $\mathrm{F}_{\text {hitung }}>\mathrm{F}_{\text {tabel }}$ artinya bahwa populasi tersebut memiliki varians yang sama. Setelah diketahui data berasal dari populasi yang sama.

Tabel 4. Hasil Uji Homogenitas Posttest Dan Pretest Kelas Kontrol Dan Kelas Eksperimen

\begin{tabular}{|c|c|c|}
\hline \multirow[t]{2}{*}{ Data } & \multicolumn{2}{|c|}{$\begin{array}{c}\text { Statistik } \\
\text { Uii Leneve's ( Sig } \geq 0,05)\end{array}$} \\
\hline & Pretest & Posttest \\
\hline $\begin{array}{l}\text { Eksperimen } \\
\text { Kontrol }\end{array}$ & 0,622 & 0,06 \\
\hline Kesimpulan & \multicolumn{2}{|c|}{ Varians Homogen } \\
\hline
\end{tabular}

Dikarenakan nilai Pretest pada kelas eksperimen tdak berdistribusi normal maka untuk uji hipotesis menggunakan statistik non parametrik yaitu uji Maan-Whitney.

3. Hasil Pengujian Hipotesis

Pengujian hiposkripsi ini menggunakan uji Mann-Whitney pada aplikasi statistik SPSS 17. Dari tabel 4 terdapat nilai yang tidak berdistribusi normal namun memiliki varian yang homogen sehingga dilakukan uji statistik non paramaterik. Berikut hasil uji menggunakan Mann-Whitney.

Tabel 5. Mann-Whitney U-Test

\begin{tabular}{|l|l|}
\hline Data & $\begin{array}{l}\text { Normalias_Hasil_Be } \\
\text { lajar }\end{array}$ \\
\hline Mann-Whitney U & 40.500 \\
Wilcoxon W & 635.500 \\
Z & -6.664
\end{tabular}


\begin{tabular}{l}
$\begin{array}{l}\text { Asymp. } \\
\text { tailed })\end{array}$ \\
\hline
\end{tabular}

Dari tabel di atas diketahui bahwa hasil uji hipotesis menunjukkan nilai signifikansi lebih kecil dari 0,05 (0,000). Sehingga hipotesis $\mathrm{H}_{0}$ diterima. Dengan demikian, dapat dikatakan bahwa terdapat perbedaan hasil belajar antara kelas ekperimen yang belajar menggunakan model kooperatif tipe Course Review Horay (CRH) dengan kelas kontrol yang belajar dengan menggunakan model Discovery Learning.

4. Hasil Pengujian Efektivitas

Pengujian effect size ini mempunyai tujuan untuk melihat apakah model pembelajaran yang digunakan peneliti efektiv dalam suatu pembelajaran, serta melihat tingkatan pengaruh variabel bebas yaitu model pembelajaran $\mathrm{CRH}$ (Course Review Horay) terhadap variabel terikat yaitu nilai kognitif (hasil belajar) yang ditinjau menggunakan effectsSize. Efektivitas dapat diketahui dengan dihitung menggunakan skala dari perbandingan gain kelas perlakuan dengan kelas kontrol dengan standar deviasinya.

Dari pengujian efektivitas dengan menggunakan effect size didapatkan nilai dari uji effect size yaitu 1,41 yang termasuk dalam kategori tinggi $(\mathrm{d}=1,41>0,8)$. Dengan demikian dapat disimpulkan pada peneltian ini yaitu model pembelajaran kooperatif tipe CRH (Course Review Horay) efektif dalam meningkatkan hasil belajar peserta didik .

Nilai uji $N$-Gain melihatkan selisih antara nilai pretest dan post-test baik pada kelas eksperimen ataupun kelas kontrol, yang tercantum pada tabel 4.3. Nilai ratarata $N$-Gain kelas eksperimen mendapatkan nilai 0,66 dengan kategori sedang. Kemudian untuk nilai rata-rata $\mathrm{N}$-Gain kelas kontrol 0,43 dengan kateori sedang pula.
Dari penjelasan diatas menerangkan bahwa terdapat perbedaan yang signifikan. Perbedaan yang signifikan pada $\mathrm{N}$-Gain ini menunjukan bahwa kelas eksperimen terdapat peningkatan hasil belajar yang lebih baik dibandingkan kelas kontrol. Keadaan ini juga yang mendasari berhasilnya model pembelajaran $\mathrm{CRH}$ (Course Review Horay) dalam meningkatkan nilai kognitif peserta didik..

Hal yang mendukung model pembelajaran kooperatif tipe $\mathrm{CRH}$ (Course Review Horay) yaitu berdasarkan nilai kognitif penelitian yang dilakukan oleh Dewi Rahimah dkk, maka kesimpulannya yaitu penerapan model pembelajaran course review horay dengan bantuan media berupa macromedia dapat meningkatkan hasil belajar.(Damayanti, Rosilawati, \& Fadiawati, 2018)

\section{KESIMPULAN DAN SARAN Kesimpulan}

Berdasarkan deskripsi data dan pembahasan maka peneliti memperoleh kesimpulan bahwa penggunaan model pembelajaran kooperatif tipe $\mathrm{CRH}$ (Course Review Horay) terhadap hasil belajar mengalami peningkatan hal tersebut diuktikan pada nilai rata-rata posttest peserta didik kelas eksperimen lebih tinggi dibandingkan kelas kontrol. Hasil uji $\mathrm{N}$ Gain menunjukan terdapat selisih antara nilai pretest dan post-test baik pada kelas eksperimen maupun kelas control

\section{Saran}

Berdasarkan pembahasan dan kesimpulan dalam penelitian ini, peneliti memberikan saran sebagai berikut:

1. Dalam mengajar perlu digunakannya pembelajaran yang bervariasi, karena tidak semua materi cocok dengan satu model pembelajaran. 
2. Pemilihan pembelajaran yang bervariasi dan tepat dapat mempengaruhi hasil belajar dan penguasaan keterampilan proses sains peserta didik terhadap mata pelajaran tersebut.

3. Perlu adanya penelitian lanjutan mengenai efektivitas model pembelajaran kooperatif tipe $\mathrm{CRH}$ (Course Review Horay) terhadap hasil belajar dan keterampilan proses sains.

\section{DAFTAR PUSTAKA}

Afandi, M., Evi, C., \& Puspita Wardani Oktarina. (2013). Model dan Metode Pembelajaran Sekolah.

Ani, ni kadek, Garminah, ni nyoman, \& Suartama, i kadek. (2016). PENGARUH MODEL PEMBELAJARAN CRH BERBANTUAN LKS SISWA KELAS IV SD. E-Journal PGSD Universitas Pendidikan Ganesha, 4(1).

Aris, S. (2014). 68 Model Pembelajaran Inovatif Dalam Kurikulum 2013.

Damayanti, R., Rosilawati, I., \& Fadiawati, N. (2018). Efektivitas LKS Larutan Penyangga Berbasis Discovery Learning untuk Meningkatkan KPS Ditinjau dari Kemampuan Kognitif, 7(1), 154-168.

Desy, P., Sari, K., \& Tastra, I. D. K. (2016). Pengaruh Model Pembelajaran Course Review Horay ( $\mathrm{CRH}$ ) Berbantuan Media Benda Kongkrit Belajar IPA. EJournal PGSD Universitas Pendidikan Ganesha Jurusan PGSD, (1).

Diani, R., Yuberti, \& Syafitri, S. (2016). Uji Effect Size Model Pembelajaran Scramble Dengan Media Video Terhadap Hasil Belajar Fisika Peserta Didik Kelas X Man 1 Pesisir Barat, 5(2), 265-275. https://doi.org/10.24042/jpifalbiruni.v5 i2. 126
Haris, A., \& Amal, A. (2016). Pendidikan Dicerminkan Pada Terselenggaranya Proses Belajar Mengajar Yang Efektif Didalam Kelas Ynag Didukung Oleh Sarana Dan Prasana Yang Memadai, Misalnya Media, Bahan Ajar dan Lingkungan. Jurnal Sains Dan Pendidikan Fisika, 12(1).

Indrawati, A. W. T., \& Harijanto, A. (2017). Implementasi Model GI-GI (Group Investigation-Guided Inquiry) Pada Pembelajaran Momentum dan Implus di MAN. Jurnal Pembelajaran Fisika, 6(3), 256.

Komikesari, H. (2016). Peningkatan Keterampilan Proses Sains Dan Hasil Belajar Fisika Siswa Pada Model Pembelajaran Kooperatif Tipe Student Team Achievement Division. Jurnal Keguruan Dan Ilmu Tarbiyah 01 (1) (2016) 15-22, 1(1), 15-22.

Mahanani, E. P., Suhito, \& Mashuri. (2013). Keefektifan Model Course Review Horay Berbantuan Powerpoint Pada Kemampuan Pemecahan Masalah Siswa. Unnes Journal of Mathematics Education, 2(2252).

meidian kusumawati. (2014). Keefektifan Model Course Review Horay Terhadap Peningkatan Hasil Belajar IPS. Journal of Elementary Education, 1-.

Pramadita, A. A., Mashuri, \& Arifudin, R. (2013). Keefektifan Model Pembelajaran Course Review Horray Terhadap Hasil Belajar Dan Minat Belajar Siswa. Unnes Journal of Mathematics Education, 2(2).

Rozi, F. (2014). penerapan model pembelajaran kooperatif tipe course review horay (crh) pada materi memelihara transmisi untuk meningkatkan hasil belajar siswa kelas xi tkr 3 smk pgri 1 lamongan, 2, 7681.

Saregar, A., Marlina, A., \& Kholid, I. 
(2017). 'Efektivitas Model

Pembelajaran Arias Ditinjau Dari Sikap Ilmiah: Dampak Terhadap Pemahaman Konsep Fluida Statis. Jurnal Ilmiah Pendidikan Fisika AlBiruni, 6(2), 255-263. https://doi.org/10.24042/jipfalbiruni.v6 i 2.2181

Setiyaningsih. (2014). Peningkatan Aktivitas Dan Hasil Belajar Bentuk Pasar Dengan Metode Course Review Horay (Crh) Berbantuan Media Gambar Kelas Viii Smp N 1 Bulu Kabupaten Sukoharjo. Economic Education Analysis Journal, 2(3).

Sugianti, U., \& Lesmono, A. D. S. (2017). Pengaruh Model Pembelajaran Cooperative Integrated Reading And Composition (CIRC) di Sertai Permasalahan Plikatif Terhadap Motivasi dan Hasil Belajar Siswa Dalam Pembelajaran Fisika di SMAN 2 Tanggul pada materi Kinematika Gerak. Jurnal Pembelajaran Fisika, 6(3), 225. 